\title{
Surgical release for tubercular elbow stiffness
}

This article was published in the following Dove Press journal:

Infection and Drug Resistance

\author{
Yun Qian ${ }^{1,2, *}$ \\ Qixin $\operatorname{Han}^{3, *}$ \\ Wei Wang ${ }^{1,2, *}$ \\ Yuanming Ouyang ${ }^{1,2}$ \\ Weien Yuan ${ }^{4}$ \\ Cunyi Fan' \\ 'Department of Orthopedics, \\ Shanghai Jiao Tong University Affiliated \\ Sixth People's Hospital, ${ }^{2}$ Department \\ of Orthopedics, Shanghai University \\ of Medicine and Health, Shanghai \\ Sixth People's Hospital East Campus, \\ ${ }^{3}$ Renji Hospital, School of Medicine, \\ ${ }^{4}$ School of Pharmacy, Shanghai Jiao \\ Tong University, Shanghai, China \\ *These authors contributed equally to \\ this work
}

Correspondence: Yuanming Ouyang; Cunyi Fan

Shanghai Jiao Tong University Affiliated Sixth People's Hospital, 600 Yishan Road, Shanghai Shanghai 200233, China Tel +86 I36 8I66 5I83 Email ouyangyuanming@163.com; cyfan@sjtu.edu.cn
Background: For decades, tuberculosis (TB) has posed a great threat to people worldwide. Bone and joint TB is one of the most common types of extrapulmonary TB, with elbow TB comprising a small proportion of these cases. The treatment for elbow stiffness associated with TB has been rarely reported.

Patients and methods: We retrospectively analyzed six patients (four females and two males) with tubercular elbow stiffness during a 7-year period. All of them received open arthrolysis and hinged external fixation to restore functional extension, flexion, supination and pronation. Mayo Elbow Performance Score (MEPS) and range of motion (ROM) were evaluated preoperatively and at final follow-up.

Results: At final follow-up after surgery, we evaluated the average active ROM, which was $111.7^{\circ}\left(90^{\circ}-135^{\circ}\right)$. The average extension was $11.7^{\circ}\left(0^{\circ}-30^{\circ}\right)$, while the average flexion was $123.3^{\circ}\left(115^{\circ}-135^{\circ}\right)$. At the same time, the average supination was increased to $70^{\circ}\left(40^{\circ}-90^{\circ}\right)$ and the average pronation was increased to $68.3^{\circ}\left(45^{\circ}-80^{\circ}\right)$. The MEPS was elevated to 92.5 (85-100). Three patients displayed complications and were treated and cured with dressing changes and antibiotics.

Conclusion: Open arthrolysis and hinged external fixation are useful for the treatment of nontraumatic elbow stiffness with TB.

Keywords: open arthrolysis, hinged external fixation, non-traumatic, heterotopic ossification

\section{Background}

Elbow stiffness is one of the major causes for the loss of elbow function and activity, which is categorized into traumatic and non-traumatic elbow stiffness. Injury, burn and brain damage are the major causes for the post-traumatic elbow restriction. ${ }^{1-3}$ The causes of non-traumatic elbow stiffness include osteoarthritis, congenital radial head dislocation and so forth. ${ }^{4}$ Tubercular elbow stiffness is uncommon in some developed countries. However, it is quite prevalent where tuberculosis (TB) is epidemic. ${ }^{5}$

TB has attracted wide attention in the past several decades for its highly contagious and deadly characteristics. Although according to WHO, the number of TB infections keeps declining at a rate of 4\% per year from 1990 to 2010 in China, ${ }^{6}$ the overall population of active TB infection was estimated to reach over 5 million in 2000, among whom $>100,000$ patients lost their lives each year. ${ }^{7}$ The number of TB infections is decreasing by only $1 \%$ every year worldwide. ${ }^{8}$ Mycobacterium tuberculosis is the pathogen that causes TB. In less developed regions, people are easily infected by these bacteria. The overall trend for this disease remains more common in rural areas of large cities. ${ }^{9} \mathrm{~TB}$ 
is considered as a kind of respiratory disease which mainly attacks the lung and trachea. Extrapulmonary TB usually occurs in brain, intestine and urinary and bone systems, resulting in the delay of accurate diagnosis and necessary treatment. ${ }^{10} \mathrm{~A}$ total of $10 \%-18 \%$ of all extrapulmonary TB cases are bone and joint TB infection. ${ }^{11,12}$ In addition, it is the third most common site of extrapulmonary TB in many countries. ${ }^{13}$ In bone and joint TB, muscular involvement leading to elbow stiffness is uncommon, both in developing and developed worlds. ${ }^{14}$ There are very few studies reporting tubercular elbow stiffness. Aggarwal and Dhammi ${ }^{15}$ presented 48 patients with elbow TB with different levels of elbow motion limitation. Therefore, medical professionals and patients need to work together to achieve ideal return of elbow function and activity. In this retrospective study, we evaluated the surgical outcomes and functional recovery of six patients who received open arthrolysis and hinged external fixation to regain functional range of motion (ROM) in their long-term rehabilitation.

\section{Patients and methods}

We performed a retrospective review of six patients (four females and two males) who experienced stiff elbow restricting normal elbow function and received surgeries and rehabilitation in Shanghai Sixth People's Hospital from January 2010 to June 2016. All the patients received open arthrolysis and hinged external fixation. We evaluated the preoperative radiological examinations, such as X-rays and computed tomography (CT), and laboratory tests to check whether these patients have positive $M$. tuberculosis infection. In addition, we also evaluated their clinical manifestation such as elbow swelling, joint pain and motion limitation. These factors highly indicated tubercular elbow stiffness and were considered as primary inclusion criteria. Patients were excluded from the study if they have the following characteristics: 1) previous surgical intervention for stiff elbow; 2) traumatic elbow stiffness resulting from accidents, brain injuries and burns and 3) previous arthroscopic treatment.

The general information of all the patients is displayed in Table 1. Three of six patients experienced preoperative heterotopic ossification. One of them was Grade II, and the other two were Grade III. ${ }^{16}$ The average preoperative ROM was $50.8^{\circ}\left(30^{\circ}-75^{\circ}\right)$. The average extension was $20^{\circ}\left(10^{\circ}-30^{\circ}\right)$. The average flexion was $70.8^{\circ}\left(50^{\circ}-95^{\circ}\right)$. The average supination was $47.5^{\circ}\left(30^{\circ}-90^{\circ}\right)$. The average pronation was $39.2^{\circ}$ $\left(15^{\circ}-60^{\circ}\right)$. The average time duration from initial restriction of elbow to being admitted for surgery was 8.5 months (6-13 months). The average Mayo Elbow Performance Score (MEPS) was 43.3 (35-55). Four of six patients experienced nerve symptoms including radial, ulnar and median nerves. Among them, three patients experienced numbness in the ring finger and little finger. The other one experienced numbness in the first web of palm. The rest showed no significant signs of nerve compression. Besides, two of six patients admitted smoke and alcohol abuse.

Before starting operation for elbow arthrolysis, we performed different tests and examinations including blood routine tests, urinary routine tests, hepatic and renal function tests, disseminated intravascular coagulation (DIC), C-reactive protein (CRP), sedimentation rate, chest X-rays, elbow anterior/posterior and lateral plain films and so forth. We observed patchy destructions in chest X-rays of three patients. The other three patients displayed plague-like shadow in X-ray films. Most of the patients displayed wormeaten like hollows in the elbow anterior/posterior and lateral plain films, indicating severe infection of M. tuberculosis (Figure 1). One patient was confirmed Treponema pallidum positive. Five of six patients complained moderate pain and the remaining one claimed to experience severe pain relieved by medication only.

Table I Patient preoperative characteristics

\begin{tabular}{|c|c|c|c|c|c|c|c|c|c|c|c|}
\hline Number & $\begin{array}{l}\text { Age } \\
\text { (years) }\end{array}$ & Gender & BMI & $\begin{array}{l}\text { Side } \\
\text { of } \\
\text { elbow }\end{array}$ & $\begin{array}{l}\text { Time of } \\
\text { restriction } \\
\text { (months) }\end{array}$ & $\begin{array}{l}\text { Extension/ } \\
\text { flexion }\end{array}$ & $\begin{array}{l}\text { Supination/ } \\
\text { pronation }\end{array}$ & MEPS & $\begin{array}{l}\text { Pulmonary } \\
\text { involvement }\end{array}$ & HO & $\begin{array}{l}\text { Previous } \\
\text { treatment }\end{array}$ \\
\hline 1 & 40 & Male & 22.5 & Left & 7 & $15^{\circ} / 60^{\circ}$ & $45^{\circ} / 15^{\circ}$ & 35 & Yes & III & 1 \\
\hline 2 & 23 & Female & 24.8 & Right & 8 & $15^{\circ} / 90^{\circ}$ & $45^{\circ} / 50^{\circ}$ & 45 & No & l & Anti-bacterial therapy \\
\hline 3 & 36 & Male & 26.3 & Left & 10 & $10^{\circ} / 80^{\circ}$ & $45^{\circ} / 50^{\circ}$ & 55 & No & II & TCM \\
\hline 4 & 38 & Female & 25.6 & Right & 7 & $30^{\circ} / 95^{\circ}$ & $90^{\circ} / 60^{\circ}$ & 45 & Yes & 1 & $\begin{array}{l}\text { Anti-tuberculosis } \\
\text { treatment }\end{array}$ \\
\hline 5 & 29 & Female & 22.1 & Left & 6 & $30^{\circ} / 50^{\circ}$ & $30^{\circ} / 30^{\circ}$ & 40 & Yes & l & l \\
\hline 6 & 47 & Female & 25.2 & Left & 13 & $20^{\circ} / 50^{\circ}$ & $30^{\circ} / 30^{\circ}$ & 40 & Yes & III & TCM \\
\hline
\end{tabular}

Notes: $\mathrm{HO}$ grading was according to the Hastings and Grahams Classification. I, no radiographical involvement; II, radiographically evident HO with extension/flexion and (or) supination/pronation limitation and III, severe limitations in range of motion for either extension/flexion plate or supination/pronation plate. "/" indicates no HO. Abbreviations: BMI, body mass index; HO, heterotopic ossification; MEPS, Mayo Elbow Performance Score; TCM, traditional Chinese medicine. 


\section{Surgical operation}

All the patients were placed in a supine position and received brachial plexus blockage as well as general anesthesia. All the surgeries were performed by the same doctor Fan CY and assisted by two experienced surgeons. Sterile tourniquet was used in all patients preoperatively.

We chose a combined medial and lateral approach. We carefully exposed the ulnar nerve and protected it with a wet gauze. The ulnar nerve was transposed subcutaneously and was free from compression under new ROM. The transverse and lateral bundles of medial collateral ligament as well as posterior capsule were removed. The triceps muscle was split and completely released to improve the elbow motion. We found a large area of infectious tissues in the deeper layer of elbow joint. They were confirmed as tuberculous foci by pathological tests (Figure 2). Then, we exposed the olecranon and distal humeral heterotopic ossification (HO) and dissected it with a chisel and rongeur forceps. We also performed olecranon fossa debridement to further increase motion recovery. Afterward, we performed osteotomy in medial epicondyle and recreated the structure of humeroulnar joint.

For the lateral incision, we used a classic extended Kocher approach. We split the extensor carpi ulnaris and anconeus muscle. In the joint cavity, a large infectious lesion was also identified as the synovial tissue, accompanied by necrotic stripping cartilages (Figure 2). We thoroughly cleared these atonic and infectious tissues to release more motion. The coronoid fossa was cleared as well, and the anterior capsule was removed.

The axis of $2.0 \mathrm{~mm} \mathrm{~K}$-wire was positioned and centered on the capitellum, confirmed by the C-arm X-ray. Then, a hinged external fixator was fixed on the operated arm, which was immobilized by four titanium nails that were drilled into the lateral humerus and radius with a distance of $8 \mathrm{~mm}$ each. After confirmation by the C-arm X-ray for the depth of each titanium nail in the bones, $\mathrm{K}$-wire was pulled out, and irrigation was performed to clear the incisions. Then, we used a suture anchor to repair the humeroulnar and collateral
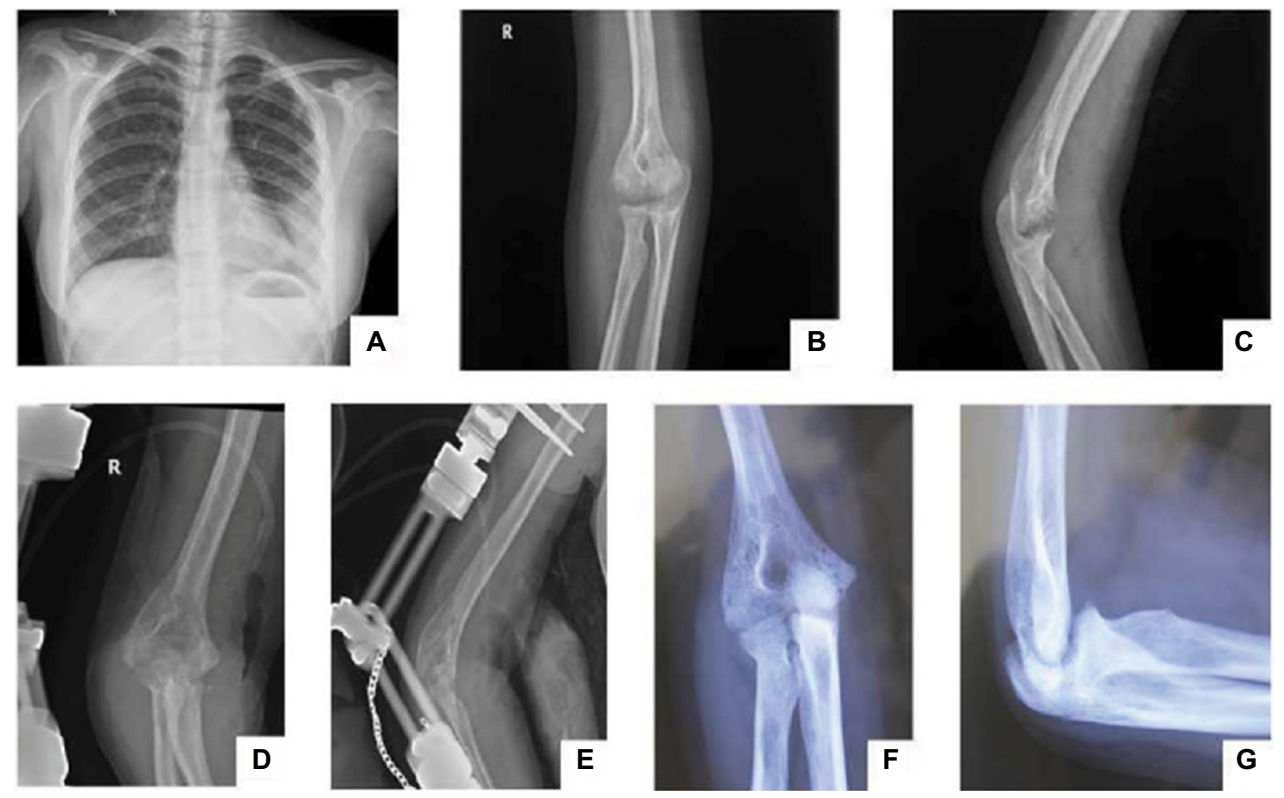

Figure I Preoperative (A-C), I-week (D and E) and I-year post-surgical elbow $\mathrm{X}$-rays (F and $\mathbf{G})$.


Figure 2 Tuberculosis infection tissue separated from the medial approach (A) and lateral approach (B). 
ligament for regaining elbow stability. Wound was sutured layer by layer. Two drainages were set aside for both lateral and medial approaches. Important patient data were recorded in follow-up recording brochure. The pathological report showed that the broken bone tissue samples were granulation tissue hyperplasia with vast necrotic tissues, which confirmed the diagnosis of elbow TB.

\section{Postoperative management}

Patients were asked to take celecoxib (200 mg each pill) thrice a day for 6 weeks to prevent HO recurrence. They started passive motion practice immediately on postoperative day 1 . All the patients must achieve extension of $0^{\circ}$ and flexion of $120^{\circ}-130^{\circ}$ with active and passive exercises which contributed to better and faster recovery. The elbow was suggested to be positioned at flexion or extension angle at alternate sleep. Anti-tubercular therapy was continued after patients were discharged.

The hinged external fixator was removed after 6-8 weeks postoperatively when patients visited outpatient clinic for follow-ups. Radiological examination was carried out for the patients on postoperative day 1, 6 weeks, 3 and 6 months, as well as 1 year, respectively. We would evaluate potential recurrent heterotopic ossification, as well as the state of overall elbow structures. No patients received radiotherapy in this series.

\section{Ethical approval}

The ethics committee of Shanghai Jiao Tong University Affiliated Sixth People's Hospital concluded that no approval was necessary for the study based on its retrospective design. Data were analyzed anonymously; all patients approved the results of this study and use of their photos for publication by oral and written consent. The consent approval was documented in the patients' files, which was approved by the ethics committee of Shanghai Jiao Tong University Affiliated Sixth People's Hospital. All clinical investigations were conducted in accordance with the guidelines of the Declaration of Helsinki.

\section{Results}

The mean follow-up period was 12 months (9-16 months). At final follow-ups after surgery, we evaluated the average active ROM which was $111.7^{\circ}\left(90^{\circ}-135^{\circ}\right)$ and was improved by $60.9^{\circ}$ compared with preoperative average active ROM. The average extension was $11.7^{\circ}\left(0^{\circ}-30^{\circ}\right)$ and showed decrease of $8.3^{\circ}$ compared with the preoperative value. The average flexion was $123.3^{\circ}\left(115^{\circ}-135^{\circ}\right)$ and was increased by $52.5^{\circ}$ compared with the preoperative value. At the same time, the average supination was increased by $22.5^{\circ}-70^{\circ}\left(40^{\circ}-90^{\circ}\right)$, and the average pronation was increased by $29.1^{\circ}-68.3^{\circ}$ $\left(45^{\circ}-80^{\circ}\right)$. The MEPS was elevated by 49.2-92.5 (85-100) (Table 2). Figures 1, 3 and 4 display preoperative and 1-year post-surgical ROM performance and the preoperative, 1-week and 1-year post-surgical radiological evaluation of patient 4 in this case series. From all the radiographs taken after surgery, only one TB recurrent case occurred and was considered insignificant since it did not restrict the elbow motion of patients.

Besides, no elbow instability was found in any patients in the follow-ups. This was consistent with the preoperative findings that no patients exhibited lateral or medial instability of the elbow joint.

As for postoperative complications, one pin site superficial infection, and one pin site erythema occurred within 1 month after surgery, along with a case of joint cavity edema and infection at 2 months postoperatively. The local infection was treated with appropriate management, like dressing change on alternate day.

\section{Discussion}

TB infection is increasing slowly every year due to reasonable management and prevention worldwide. However, in rural areas, it is still a major cause of death or morbidities. ${ }^{17}$

Table 2 Operative data and postoperative follow-ups

\begin{tabular}{|c|c|c|c|c|c|c|c|}
\hline Number & $\begin{array}{l}\text { Ligament } \\
\text { remodeling }\end{array}$ & $\begin{array}{l}\text { Extension/ } \\
\text { flexion }\end{array}$ & $\begin{array}{l}\text { Supination/ } \\
\text { pronation }\end{array}$ & MEPS & $\begin{array}{l}\text { Recurrent } \\
\text { HO }\end{array}$ & $\begin{array}{l}\text { Other } \\
\text { complications }\end{array}$ & $\begin{array}{l}\text { Follow-up duration } \\
\text { (months) }\end{array}$ \\
\hline I & MCL and LCL & $0^{\circ} / 135^{\circ}$ & $50^{\circ} / 80^{\circ}$ & 100 & No & I & 9 \\
\hline 2 & $\mathrm{LCL}$ & $30^{\circ} / 120^{\circ}$ & $80^{\circ} / 65^{\circ}$ & 95 & No & I & 12 \\
\hline 3 & $M C L$ and $L C L$ & $20^{\circ} / 120^{\circ}$ & $80^{\circ} / 80^{\circ}$ & 90 & I & Pin site superficial infection & 10 \\
\hline 4 & MCL and $L C L$ & $10^{\circ} / 120^{\circ}$ & $90^{\circ} / 45^{\circ}$ & 90 & No & Pin site erythema & 12 \\
\hline 5 & LCL & $0^{\circ} / 115^{\circ}$ & $40^{\circ} / 70^{\circ}$ & 85 & No & 1 & 13 \\
\hline 6 & $M C L$ and $L C L$ & $10^{\circ} / 130^{\circ}$ & $80^{\circ} / 70^{\circ}$ & 95 & No & Joint cavity edema and infection & 16 \\
\hline
\end{tabular}

Note: "l" indicates no other complications.

Abbreviations: HO, heterotopic ossification; LCL, lateral collateral ligament; MCL, medial collateral ligament; MEPS, Mayo Elbow Performance Score. 

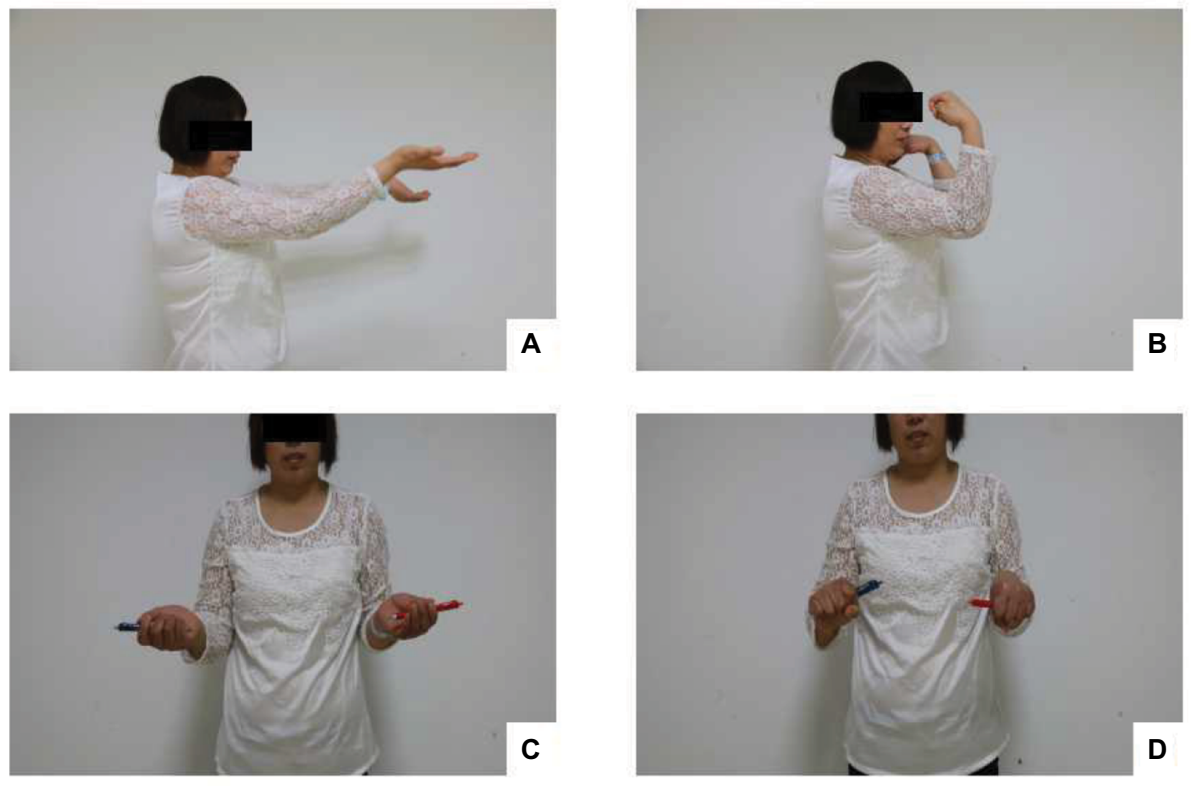

Figure 3 Preoperative extension (A), flexion (B), supination (C), and pronation of patient 4 (D).
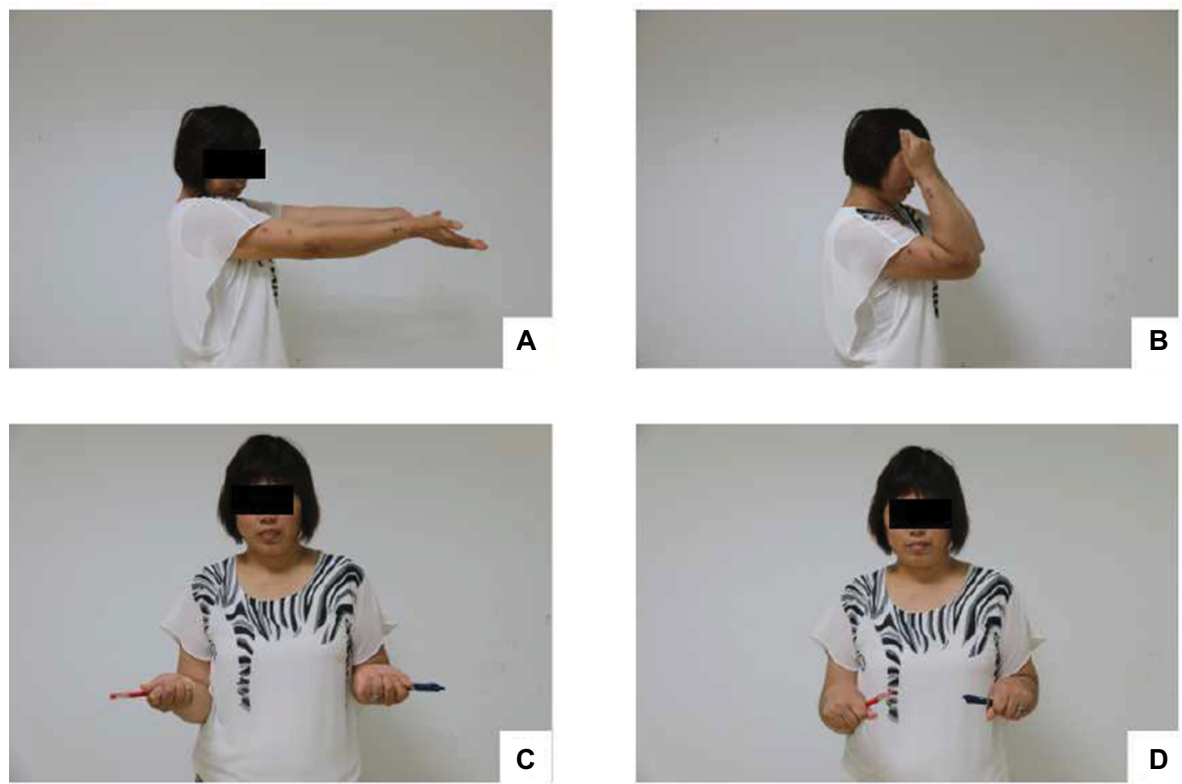

Figure 4 I-year post-surgical extension (A), flexion (B), supination (C), and pronation of patient 4 (D).

Among all the TB infections, upper extremity TB only accounts for $10 \%$ of bone and joint TB infections. The elbow TB represents even more unusual. ${ }^{18,19}$ It is the tubercular osteomyelitis and a secondary complication for pulmonary TB. ${ }^{20}$ Under such circumstances, the bacteria usually spread through the circulatory system and attack the long bones, muscles and especially synovium because of its relatively high oxygen concentration. ${ }^{21,22}$ Patients usually complain about elbow edema, swelling and ulcerations with purulent secretion, as well as general symptoms such as unexplained weakness, fatigue or weight decline. ${ }^{23-25}$
At the same time, acute fracture around the elbow joint was never found. Surgeons only observed partial or complete erosion of humeral, ulnar or radial ends from X-rays. ${ }^{26}$ Antibiotics were subscribed to patients, but they showed no relief of pain. ${ }^{27}$ Atypical radiological performance and clinical features always delayed the correct diagnosis and proper treatment. ${ }^{15}$ To our best knowledge, there were few reports about surgical release of TB-related elbow motion restriction that eventually led to elbow stiffness previously. In this study, the surgical treatment of this disorder was thoroughly evaluated. 
Arthroscopic operation is often used for non-traumatic elbow stiffness or mild motion restriction. ${ }^{28}$ However, an open release was more appropriate to avoid damaging neurovascular tissues nearby due to the massive structural destruction and major reconstruction of relevant joints and ligaments. There are plenty of approaches to solve the elbow contracture according to different literature. ${ }^{29}$ They all have their merits and defects. The anterior approach is good for releasing flexion contracture. However, the disadvantages are very obvious such as potential neurovascular complications and failure to expose the posterior structure of the elbow joint, like the olecranon fossa. Aldridge et a ${ }^{30}$ reported the surgical outcomes and long-term follow-ups of 106 patients who received open arthrolysis for elbow stiffness with an anterior surgical approach at their institute. The findings revealed that 11 complications including traction neuropathies, superficial and deep infection occurred in spite of relatively ideal improvement of flexion and extension after surgery. ${ }^{30}$ The posterior approach is also common in the open release for stiff elbow. It has many advantages such as simultaneous release of anterior, posterior, medial and lateral directions. However, massive stripping of soft tissues may lead to high tension of the incision, subcutaneous hematoma and skin necrosis. ${ }^{31}$ In this series, another major concern for avoiding a posterior approach was the regional spreading of M. tuberculosis. The purpose for arthrolysis for elbow stiffness with TB was to relieve the motion restriction and to remove infectious tissues. Massive stripping of a posterior approach would leave more unaffected soft tissues and vessels exposed to M. tuberculosis, which was likely to cause severe hematogenous spread to other regions and finally even general infection. Surgeons can fully expose the ulnar nerve and transpose it later via a medial approach. However, it cannot solve radial head problems or fix lateral collateral ligament. ${ }^{32}$ In addition, surgeons cannot expose the ulnar nerve and relieve nerve symptoms of patients via a lateral approach. ${ }^{33}$ Conclusively speaking, a combination of lateral and medial approach was beneficial for treating the above situations and limiting the potential TB spread. This combined approach enabled these patients to enjoy a full ROM recovery in the operation, with flexion of $135^{\circ}$ and extension of $0^{\circ}$.

The common flexor tendon and the common extensor tendon were very vulnerable after open arthrolysis. A hinged external fixator was applied in this study in order to further ensure the elbow stability. This assistant device has many advantages such as prevention of lateral displacement, protection of articular structures and early elbow motion practice immediately after operation. ${ }^{34}$
As mentioned earlier, TB could affect and devastate the synovial construction in most cases. The $\mathrm{HO}$ was actually not a major complication for elbow TB patients. In this series, half of the patients displayed HO preoperatively. These patients either accepted traditional Chinese medicine or had no previous treatment. It was proposed that the medication they received probably induced HO occurrence. The side effects could contribute to ectopic bone development because the ingredients might promote blood circulation.

Patients should take the anti-tubercular drugs as early as possible to control disease progress. Nevertheless, their side effects, like articular edema, and joint pain were potentially harmful to elbow function and motion recovery, especially at an early stage. ${ }^{35}$ In order not to interfere with rehabilitation exercise at the early stage, they did not take anti-tubercular medication in hospital. Therefore, all patients were recommended to start anti-tubercular therapy after being discharged. They were advised to go to a specialized infectious disease department or hospital. They received regular anti-tubercular treatment for 6-12 months.

Postoperative infection was pretty common in TB patients because they were generally immunocompromised. Among six patients in this series, half of them displayed different complications including one pin site superficial infection, one pin site erythema, one joint cavity edema and infection at 1 and 2 months after operation, respectively. One patient was also infected with T. pallidum that further reduced the immunity. Patients received wound dressing change and antibiotics. All of them returned to a stable condition after 2 weeks of treatment. No postoperative nerve symptoms occurred at 1, 3, 6 and 12 months of follow-ups, indicating a successful transposition of the ulnar nerve. A patient experienced numbness in thumb-index web of the palm preoperatively. His nerve symptom also disappeared after surgery and in the long-term follow-up.

There were plenty of factors that determined the eventual prognosis for elbow stiffness with TB infection. Perseverance in passive and active elbow exercises and physical therapies was very important for maximizing the elbow ROM achieved during surgery. A continuous active and passive movement contributed to prevention of articular adhesion and recovery of muscle strength. All patients received passive elbow motion exercise on postoperative day 1 . With the help of a physical therapist from our hospital, the patients needed to complete 30 times of flexion and extension exercise. It was doubled on day 2 with 60 times. On day 7, all patients needed to complete 150 times of extension and flexion exercise. From day 3 postoperatively, they started to exercise by themselves 
in order to regain muscle strength. Another significant factor was pain control. All the patients used postsurgical analgesia pump for the first 24 hours and simultaneous intravenous drips of Flurbiprofen to make sure they could endure certain pain and keep functional practice.

There are several limitations in this study. First, this is a retrospective research and therefore the design has some defects. Second, the sample size is very small although elbow stiffness resulting from TB is very rare. In the future, we want to add more cases to further discuss the potential significance of arthrolysis for tubercular elbow stiffness. In addition, we should include control group in this study to better show the beneficial effects of surgical release of tubercular stiff elbow.

\section{Conclusion}

In this study, an open release combined with lateral and medial surgical approach was adopted in the arthrolysis for elbow stiffness with TB, along with the application of unilateral hinged external fixator for stabilizing elbow joint. The successful surgical operation and satisfactory rehabilitation with long-term active and passive motion practice provide us with new insights to the overall treatment of stiff elbow with TB.

\section{Acknowledgments}

The study was supported by Projects of the Shanghai Committee of Science and Technology, China (No. 12XD1403800), SUMHS seed foundation project (No. HMSF-16-21-010), Natural Science Foundation of Shanghai (15ZR1432500 and 14712400304), Funds for Interdisciplinary Projects of Medicine and Engineering of Shanghai JiaoTong University (No. YG2017MS22, YG2015MS06, YG2017QN56, and YG2016QN22) and Science and Technology Development Foundation of Pudong New District, Shanghai, China (PKJ2016-Y55 and PWZxq2017-03).

\section{Author contributions}

All authors equally contributed toward data analysis, drafting and revising the paper and agree to be accountable for all aspects of the work.

\section{Disclosure}

The authors, their immediate families and any research foundation with which they are affiliated have not received any financial payments or other benefits from any commercial entity related to the subject of this article. The authors report no conflicts of interest in this work.

\section{References}

1. Baldwin K, Hosalkar HS, Donegan DJ, Rendon N, Ramsey M, Keenan MA. Surgical resection of heterotopic bone about the elbow: an institutional experience with traumatic and neurologic etiologies. $J$ Hand Surg Br. 2011;36(5):798-803.

2. Bornu BC, Clément X, Kempf JF, Clavert P. Arthroscopic elbow joint release with radial head resection arthroplasty: 12 cases. Orthop Traumatol Surg Res. 2015;101(6):735-739.

3. Salazar D, Golz A, Israel H, Marra G. Heterotopic ossification of the elbow treated With surgical resection: risk factors, bony ankylosis, and complications. Clin Orthop Relat Res. 2014;472(7):2269-2275.

4. Thoreux P, Blondeau C, Durand S, Masquelet AC. Anatomical basis of arthroscopic capsulotomy for elbow stiffness. Surg Radiol Anat. 2006;28(4):409-415.

5. Martini M, Benkeddache Y, Medjani Y, Gottesman H. Tuberculosis of the upper limb joints. Int Orthop. 1986;10(1):17-23.

6. Lin HH, Wang L, Zhang H, Ruan Y, Chin DP, Dye C. Tuberculosis control in China: use of modelling to develop targets and policies. Bull World Health Organ. 2015;93(11):790-798.

7. Bele S, Jiang W, Lu H, et al. Population aging and migrant workers: bottlenecks in tuberculosis control in rural China. PLoS One. 2014;9(2):e88290.

8. Jassal MS, Bishai WR. Epidemiology and challenges to the elimination of global tuberculosis. Clin Infect Dis. 2010;50(suppl_3):S156.

9. Tobin-West CI, Isodje A. Quality and rural-urban comparison of tuberculosis care in Rivers State, Nigeria. Pan Afr Med J. 2016;24:60.

10. Sunnetcioglu A, Sunnetcioglu M, Binici I, Baran AI, Karahocagil MK, Saydan MR. Comparative analysis of pulmonary and extrapulmonary tuberculosis of 411 cases. Ann Clin Microbiol Antimicrob. 2015;14(1):34.

11. Chen ST, Zhao LP, Dong WJ, et al. The clinical features and bacteriological characterizations of bone and joint tuberculosis in China. Sci Rep. 2015;5:11084.

12. Ruiz G, García Rodríguez J, Güerri ML, González A. Osteoarticular tuberculosis in a general hospital during the last decade. Clin Microbiol Infect. 2003;9(9):919-923.

13. Sandgren A, Hollo V, van der Werf MJ. Extrapulmonary tuberculosis in the European Union and European Economic Area, 2002 to 2011. Euro Surveill. 2013;18(12):20431.

14. Garg KM, Joshi M, Joshi N. Tubercular intramuscular abscess: an unusual presentation of tuberculosis. Curr Med Trends. 2002;6:1174-1176.

15. Aggarwal A, Dhammi I. Clinical and radiological presentation of tuberculosis of the elbow. Acta Orthop Belg. 2006;72(3):282-287.

16. Chen S, Yu SY, Yan H, et al. The time point in surgical excision of heterotopic ossification of post-traumatic stiff elbow: recommendation for early excision followed by early exercise. J Shoulder Elbow Surg. 2015;24(8): $1165-1171$.

17. Méda ZC, Huang CC, Sombié I, et al. Tuberculosis in developing countries: conditions for successful use of a decentralized approach in a rural health district. Pan Afr Med J. 2014;17:198-198.

18. Bassir RA, Saoudi F, Ismael F, et al. Bifocal musculoskeletal tuberculosis in upper limb: unusual case. Int J Mycobacteriol. 2014;3(3):217.

19. Wong JY, Chin D, Fung H, Li A, Wong MM, Kwok HK. Upper limb musculoskeletal complaints among technicians working in a diagnostic tuberculosis laboratory: two case reports. Work. 2014;48(4):547-552.

20. Remaschi G, Venturini E, Romano F, et al. A rare cause of osteomyelitis with a rare genetic mutation: when Mycobacterium doesn't only mean tuberculosis. Int J Tuberc Lung Dis. 2015;19(8):999.

21. Ko JM, Park HJ, Kim CH. Clinicoradiologic evidence of pulmonary lymphatic spread in adult patients with tuberculosis. AJR Am J Roentgenol. 2015;204(1):38-43.

22. Kong Y, Subbian S, Cirillo SLG, Cirillo JD. Application of optical imaging to study of extrapulmonary spread by tuberculosis. Tuberculosis. 2009;89(suppl 1):S15-S17.

23. Mulenga H, Tameris MD, Luabeya KK, et al. The role of clinical symptoms in the diagnosis of intrathoracic tuberculosis in young children. Pediatr Infect Dis J. 2015;34(11):1157-1162. 
24. Nihues SSE, Mancuzo EV, Sulmonetti N, et al. Chronic symptoms and pulmonary dysfunction in post-tuberculosis Brazilian patients. Braz J Infect Dis. 2015;28(5):492-497.

25. Rao VG, Bhat J, Yadav R, Gopi PG, Selvakumar N, Wares DF. Prevalence of pulmonary tuberculosis among the Bharia, a primitive tribe of Madhya Pradesh, central India. Int J Tuberc Lung Dis. 2010;14(3):368.

26. Vijay PG, Joseph MV. Retrospective analysis of varied clinical presentations and delayed diagnosis in tuberculosis affection of extremities. J Orthop Case Rep. 2012;2(3):12.

27. Domingo A, Nomdedeu M, Tomás X, García S. Elbow tuberculosis: an unusual location and diagnostic problem. Arch Orthop Trauma Surg. 2005;125(1):56-58.

28. Wu X, Hong W, Meng C, et al. Outcomes of arthroscopic arthrolysis for the post-traumatic elbow stiffness. Knee Surg Sports Traumatol Arthrosc. 2014;23(9):1-6.

29. Kodde IF, Van RJ, Mp VDB, Eygendaal D. Surgical treatment of posttraumatic elbow stiffness: a systematic review. J Shoulder Elbow Surg. 2013;22(4):574-580.
30. Aldridge JM 3rd, Atkins TA, Gunneson EE, Urbaniak JR. Anterior release of the elbow for extension loss. J Bone Joint Surg Am. 2004;86(9): 1955-1960.

31. Visna P, Kalvach J, Beitl E, Pilný J, Cizmár I. Open posterior dislocation of the elbow with fractures of the radial head and coronoid process and multiple diaphyseal fractures of the ulna. Unfallchirurg. 2008;111(3):193.

32. Mansat P, Bonnevialle N, Werner B. [Indications and technique of combined medial and lateral column procedures in severe extrinsic elbow contractures]. Orthopade. 2011;40(4):307-315.

33. Cohen MS, Hastings H 2nd. Post-traumatic contracture of the elbow. Operative release using a lateral collateral ligament sparing approach. J Bone Joint Surg Br. 1998;80(5):805-812.

34. Zhou Y, Cai JY, Chen S, Liu S, Wang W, Fan CY. Application of distal radius-positioned hinged external fixator in complete open release for severe elbow stiffness. J Shoulder Elbow Surg. 2017;26(2):e44-e51.

35. Shukla M, Sharma A, Jaiswal S, Lal J. Insights into the pharmacokinetic properties of antitubercular drugs. Expert Opin Drug Metab Toxicol. 2016;12(7):765
Infection and Drug Resistance

\section{Publish your work in this journal}

Infection and Drug Resistance is an international, peer-reviewed openaccess journal that focuses on the optimal treatment of infection (bacterial, fungal and viral) and the development and institution of preventive strategies to minimize the development and spread of resistance. The journal is specifically concerned with the epidemiology of antibiotic
Dovepress

resistance and the mechanisms of resistance development and diffusion in both hospitals and the community. The manuscript management system is completely online and includes a very quick and fair peerreview system, which is all easy to use. Visit http://www.dovepress.com/ testimonials.php to read real quotes from published authors. 